\title{
Critical Success Factors of Purchasing Polished Gemstones
}

\author{
Elimawaty Rombe, Zakiyah Zahara \\ Prodi Management Fakultas Ekonomi \\ Universitas Tadulako \\ Palu, Indonesia \\ rombeelimawaty@untad.ac.id
}

\begin{abstract}
The purpose of this study is to identify the critical factors impact the consumers' decision on purchasing polished gemstones in Indonesia. Data for this study were collected from 162 respondents with varies background whitin the city of Palu in Indonesia. There were 27 indicators tested in this study. Based on the exploratory factor analysis (EFA), there are 19 indicators support the finding of critical success factors affect consumers purchasing behavior of polished gemstones in Indonesia. Indicator (X3) has the most significant factor loadings and the supporting performance (X10) has low factor loadings The indicators are segregated in the main six factors. This research has limitation in the number of respondents involved in this study. In addition, the consumers behavior in other regions of Indonesia may have different behavior so that the further study should be tested in different regions to support the findings. This paper provide data for developing the constructs in consumers behavior of luxury products. Therefore, the future research might test and analyse the factors with other constructs with the aim to a new insight in consumer behavior of luxury products.
\end{abstract}

Keywords- critical success factors, consumers' behavior, gemstones

\section{INTRODUCTION}

Gemstones are also categorized as a luxury goods and it describes the social level of a person or user. The market of gemstones is promising after the online market have also been opened. The online transaction impact the global market of gemstones. United Stated is the largest producers and market in the world. In ASEAN context, the volume of Thailand's gemstones export have overtook the other countries in the region. However, the growth rate of Thailand have been fluctuating due to several reasons, such as, lack of law material, costs of labor, the rule of origin and environmental and consumer protection. For this reason, Indonesia have also been started to introduce gemstones since 2009. As a result, the level of sales increase in the last five years. In other words, people of Indonesia have been experiencing of gemstones fever. Many people with different level of age, social and economics, culture and religion are pooling as consumers of gemstones. In addition, there are many events have been held to promote gemstones to the public of Indonesia, such as, gemstones competition.
Gemstones of Indonesia have full of types, patterns, and unique of colors so that it could attract consumers to buy. Gemstones of Indonesia have also known with their good quality, especially when it is combined with gold or silver. Despite the characteristic of gemstones of Indonesia, consumers of gemstones could obtain another benefit, such as, treatment. There are two types of gemstones which have been used for treatment by people of Indonesia, for example, gemstones from Sojol and Marantale. Furthermore, the price of gemstones is depended on the quality of colours, clarity, size, patterns. For instance, the tounge of crocodile, ebony fossil,candel, and Jade are the most wanted for gemstones lovers. Most of the gemstones can be found in Central Sulawesi Province in Indonesia. The gemstones fever have significant impact on social economy of Indonesia people. Many people involve in this sector as trader and polisher. Therefore, this sector should be developed by the government with the aim to increase the GDP. The role of the government may provide facilities, proper regulation and help them to reach global market. Thus, the function of marketing play an important role in sustain and improving the business of gemstones. One aspect of consumers behaviour will be focused on this research.

Consumers decision have different motives depend on the interpersonal decision [1],[2],[3],[4],[5], and [6]. In the context of impression management theory, cultural aspect has big impact on the consumers decision to purchase luxury goods because they are excepted more benefits after purchase the goods [7],[8], and [9]. There are several scholars claim that socially oriented consumers is difficult to explain the motive of consumption [10],[11],[12],[13],[14], [15],[16], [17], [18], and [19]. However, purchasing luxury products involve value for individual and reference group [20]. Therefore, most of research in luxury products include social and interpersonal aspect as well as personal aspect [21], [2], [[22], [12], and [13]. Thus, this reseacrh explore what factors impact the consumers decision on purchasing gemstones which are categorised as a luxury product. In addition, there are lack of research on the customer's perception on the value of luxury product. The results of this reseacrh will fill the gap of research in luxury research literature. 


\section{LITERATURE REVIEW}

\section{A. The Concept of Luxury}

Many experts define the term of luxury as an expensive products, services or lifestyle. Luxury brands include the highest price and quality ratios products in the market [23]. Luxuries facilitate pleasure which is the object of desire. In addition, luxury is correlated to culture and represents tangible and intagible system. Tangible incudes cars, clothes, handbags, jewelry and others. Meanwhile, intangible includes behavior, ideal, and belief. Consumers able to obtain psycological and functional needs satisfaction from luxury goods. Psycological aspect is one factor that contribute to differentiate between luxury goods and non luxury goods [24]. Similarly, as [12] also claim that the definition of luxury brand contain several physical and psychological values.

Value is defined as belief for consumers to select an evaluate desirable behavior [25]. Luxury brand consumption is not only depended on financial, functional, and individual utilities, but also displaying status, success, distintion and the human desire [26]. There are two types perceptions in consumer's decision-making process, such as, personal perceptions and non-personal perceptions. Personal perceptions include perceived extended self, perceived hedonism while non personal perceptions include perceived conspicuosness, perceived uniqueness, and perceived quality.

\section{B. Dimensions of Consumer Behaviour}

There are significant debate on the consumer behavior on the luxury products. As the gemstones is categorised as luxury goods because of high price and value, it is important to acknowledge the consumers behavior. In addition, the research of consumers behavior on gemstones is not widely discussed by the scholars.

According to several scholars, personal interests of consumers influence their behavior in purchasing goods or service [8], [9]. In addition, another research found that the interpersonal influence people to purchase [3], [4], [5], [6]. However, the consumers' behavior consumption in the luxury products are different compare to other consumers. In other words, the orientation of consumers in purchasing the luxury products is not fully affected by a socially motive [12], [13], [14], [15], [16], [17], [18], [19]. The study in the customer's perception that include dimensions of psychological and functional needs is still lacking. Therefore, they suggest to mix all aspects that affect consumer's perception to buy luxury products. Several aspects that impact the customer's perception are financial, fucntional, individual, and social. Financial aspect include price, resale price, discount, and investment [27]. In addition, functional aspects include quality, uniqueness, usability, reliability, and durability of the product [26]. Furthermore, individual aspects include personal orientation, materialism, hedonistic and self identity. Then, social aspect include conspicuousness [28], [13], [16] and prestige value [12], [13], [3], [30], and [31].

\section{RESEARCH METHODOLOGY}

A survey is chosen as an appropriate research design to acknowledge the key purposes of this study. The survey was proper method to collect data about key factors of consumers decision in purchasing. This survey would help to minimise the funding to conduct the study and generalise the findings. The previous findings were examined as references for listing the key factors in the form of structured questionnaire. For this reason, the form would allow to avoid any potential bias and help to establish a model after conduct exploratory factor analysis.

The population of this study was gemstones consumers in Sulawesi Province in Indonesia. This study delivered 200 questionnaires but there were 162 respondents involved in this study successfully completed questionnaires. Respondents were asked to rate questions based on a five-point Likert Scale. The acceptable value of cronbach alpha is $\alpha>0.50$ which is similar to a suggestion of [32] that the value of 0.50 and 0.60 is acceptable in the early stages of research. In contrast, as [33] claim that the value of 0.70 and higher is usually considered for internally consistent established factors.

TABLE I. FACTORS AsSOciated With CONSUMERS PURCHASE DECISION OF GEMSTONES

\begin{tabular}{|c|c|}
\hline & Indicators \\
\hline $\mathrm{X} 1$ & Hobby \\
\hline $\mathrm{X} 2$ & modifications of shells \\
\hline $\mathrm{X} 3$ & Benefit \\
\hline $\mathrm{X} 4$ & price \\
\hline $\mathrm{X} 5$ & Trend \\
\hline X6 & variation in colors \\
\hline $\mathrm{X} 7$ & texture \\
\hline $\mathrm{X} 8$ & variations in shapes \\
\hline $\mathrm{X} 9$ & for treatment \\
\hline $\mathrm{X} 10$ & to support performances \\
\hline $\mathrm{X} 11$ & the history of gemstones \\
\hline $\mathrm{X} 12$ & public figure \\
\hline $\mathrm{X} 13$ & the original of gemstones \\
\hline $\mathrm{X} 14$ & information from family \\
\hline $\mathrm{X} 15$ & information from electronic media \\
\hline $\mathrm{X} 16$ & information from friends \\
\hline $\mathrm{X} 17$ & has a mystical value \\
\hline $\mathrm{X} 18$ & sales locations \\
\hline $\mathrm{X} 19$ & family culture \\
\hline $\mathrm{X} 20$ & self confidence \\
\hline $\mathrm{X} 21$ & as a gift \\
\hline $\mathrm{X} 22$ & family demand \\
\hline $\mathrm{X} 23$ & for fashion \\
\hline $\mathrm{X} 24$ & prestige \\
\hline $\mathrm{X} 25$ & to make friends \\
\hline $\mathrm{X} 26$ & ease to obtain \\
\hline $\mathrm{X} 27$ & risk of gold \\
\hline
\end{tabular}

Exploratory factor analysis is aimed to explore the relationship between new variables or each factor is categorised as an independent factor. There are several steps to conduct exploratory factor analysis. First of all, the t-test analysis was used via the SPSS software to ensure whether all items were significant or not. Then, those significant items would be analysed into split-half reliability. Each of subsamples was analysed in the same format to make sure if there were differences compare to the all sample. Thus, this factor analysis would establish a new model of the key factors of 
gemstones consumers purchase decision. The indicators of consumers purchase decision in this study can be seen on the Tab. I

\section{RESULTS AND DISCUSSION}

There were 100 males and 62 females involved in this study. The proportion of respondents who have the age of more than 40 years inolved in this study was almost 50 percent, while the age of 21-30was 22.2 percent, the age of 31-40 was 20.4 percent, and less than 20 years was 8 percent. In addition, the respondents' background which based on occupation level, most of the respondents was involved in this study was public service (45.1 percent), the general level was the second largets (27.2 per cent), enterpreneurs, students/college and army/police were the third, fourth and fifth largest respondents (14.2, 10.5, and 3.1 percents consecutively). Meanwhile, the proportion of respondents' income which around $\mathrm{Rp} 1.100 .000-\mathrm{Rp} 2.500 .000$ was 24.7 percent, the next level of Rp 3.600.000-Rp 5.000.000 was 24.1 percent, less than Rp. 1.000 .000 was 20.4 percent, the level of Rp 2.600.000-Rp 3.500.000 was 18.5 percent, and more than $\mathrm{Rp} 5.000 .000$ was 12.3 percent. The characteristics of respondents can be seen on the table as follow.

TABLE II. CHARACTERISTICS OF RESPONDENTS

\begin{tabular}{|c|c|c|}
\hline Profile of Respondents & Frequency & Percentage \\
\hline \multicolumn{3}{|c|}{ Gender } \\
\hline Males & 100 & 61.7 \\
\hline Females & 62 & 38.3 \\
\hline \multicolumn{3}{|c|}{ Ages } \\
\hline $20-30$ & 36 & 8.0 \\
\hline $31-40$ & 33 & 22.2 \\
\hline$>40$ & 80 & 20.4 \\
\hline \multicolumn{2}{|c|}{ Occupation level } \\
\hline Students/College & 17 & 49.4 \\
\hline Public Services & 73 & 10.5 \\
\hline Private & 44 & 45.1 \\
\hline Enterpreneurs & 23 & 27.2 \\
\hline Army / Police & 5 & 14.2 \\
\hline \multicolumn{2}{|c|}{ Salary/Income } \\
\hline 1.000 .000 & 33 & 20.4 \\
\hline $1.100 .000-2.500 .000$ & 40 & 24.7 \\
\hline $2.600 .000-3.500 .000$ & 30 & 18.5 \\
\hline $3.600 .000-5.000 .000$ & 39 & 24.1 \\
\hline$>5.000 .000$ & 20 & 12.3 \\
\hline
\end{tabular}

The mean of all indicators shows that the confidence (X20) has the largest value by 4.29 while a mistical value (X17) has the lowest value by 1.98 . Furthermore, there are 13 indicators have mean of value by 3 , but there were 9 indicators have mean of value by 2 . The mean of all indicators can be seen on the Tab. 3. The mean of all indicators which has much higher ratings can be seen as follow.

- Self confidence (X20)

- Variation in color (X6)
- Feature (X7)

- Variation in shapes (X8)

- Supporting performance (X10)

The analytical results shows that self confidence is the most important factor for consumers purchase decision of gemstone in Indonesia. Variation incolor and shapes are also considered as an important factor for consumers in Indonesia to purchase gemstones. In addition, feature of gemstones is also considered by consumers to buy the gemstones. Factor of supporting performance is also strong important. This is not surprise because the consumers need to use the gemstones for improving theirs performance.

The principal components analysis with varimax rotation is used as reference to extract factor by the researcher. According to [34], the data for factor analysis should be tested by two measurements include Bartlett's test and the KaiserMeyer-Olkin (KMO). As [35] suggested the minimum standard of 0.5 is required for analysing the factor. The eigenvalues of discontinuity is employed in this study [36]. In addition, factor loading greater than 0.6 was used to choose the factor. if the value of Kaiser-Meyer-Olkin measured of sampling adequacy is above 0.5 , the existing variables can be analysed.

The result of Kaiser-Meyer-Olkin measured of sampling adequacy is 0.634 in this study. Therefore, the 27 variables used in this study are analysed. It is aimed to acknowledge whether it can be further processed and which should be issued. The Anti Image Correlation describes the amount of Kaiser-Meyer-Olkin measured of sampling adequacy for each variable. This study found that there are several variables which have a number of Kaiser-Meyer-Olkin measured of sampling adequacy less than 0,5. According to SPSS analysis, the anti image of correlation shows that indicator of culture (X19) has value of 0.294 . Thus, this variable must be excluded and further analysis should not be included. In the second phase of testing was conducted again by involving variables that meet the requirements of the previous data processing. The study found that the value of Kaiser-Meyer-Olkin measured of sampling adequacy was 0.663 and the indicator of price (X4). As the variable has the value of anti image correlation which less than 0.5 , this variable must be excluded and further factor analysis should be conducted. Furthermore, the result of this third stage of analysis found that the value of Kaiser-Meyer-Olkin measured of sampling adequacy was 0.683 so that the next step of analysis should be taken. In other words, the indicators were further analysed.

A one-sample with $t$-test analysis with 99 percent confidence level was conducted in the preliminary. The results show that there are several of the critical success factors affecting consumers purchasing behavior in gemstones so that the next analysis can be proceded. The Cronbach's $\alpha$ coefficient for 23 factors in this study is 0.764 so that repeated analysis is not necessary. As [32] claimed that internal consistency of scale can be achieved by Cronbach's alpha value of 0.7 and upwards. 


\section{Ad anders PRESS}

According to results of this study, there are six factors established based on the eigenvalues of discontinuity greater than 1 [36]. The first factor consists of seven indicators with the eigen value of 5,049. There are several indicators are excluded because they have factor loading less than 0.60 . The indicators excluded, such as, hobby (X1), the origin of gemstone (X13) and prestise (X23). Therefore, the remaining indicators include efficacy (X3), treatment (X9), history (X11), public figure (X12). The second factor consists of seven indicators with eigen value of 4,995. This factor is supported by several variables include information from the media (X15), information from friends (X16), sales location (X18), prestige (X24), to make friends (X25), the risk of gold (X26), easy to obtain (X27).

However, informtion from media is excluded because the indicator has less than 0.6. The third factor consists of five variables with the eigen value of 3,49 . There are several ndicators support this factor, such as, modification (X2), appearance (X10), information of the family (X14), confidence (X20), other people giving them (X21). The indicator of information from family is excluded because of the factor loadings less than 0.6. The fourth factor consists three indicators with the eigen value of 2,353 . There are several variables support this factor, for example, variation in colors (X6), variation in feature (X7), variation in shapes (X8). Furthermore, the fifth factor includes only one factor with the eigen value of 0.732

TABLE III. STANDARD DEVIATION AND MEAN

\begin{tabular}{|l|c|c|}
\hline \multicolumn{1}{|c|}{ Indicator } & SD & Mean \\
\hline Hobby & 1.095 & 2,94 \\
\hline modifications of shells & 0.728 & 3,78 \\
\hline Benefit & 1.148 & 3,46 \\
\hline price & 0.482 & 3,94 \\
\hline Trend & 0.719 & 3,83 \\
\hline variation in colors & 0.356 & 4,15 \\
\hline texture & 0.596 & 4,15 \\
\hline variations in shapes & 0.483 & 4,12 \\
\hline for treatment & 1.170 & 3,06 \\
\hline to support performances & 0.366 & 4,09 \\
\hline the history of gemstones & 0.931 & 2,67 \\
\hline public figure & 1.070 & 2,81 \\
\hline the original of gemstones & 1.040 & 2,93 \\
\hline information from family & 0.858 & 2,52 \\
\hline information from electronic media & 0.956 & 3,26 \\
\hline information from friends & 0.907 & 3,52 \\
\hline has a mystical value & 1.051 & 1,98 \\
\hline sales locations & 0.864 & 3,54 \\
\hline family culture & 0.742 & 2,35 \\
\hline self confidence & 0.455 & $\mathbf{4 , 2 9}$ \\
\hline as a gift & 0.939 & 2,62 \\
\hline family demand & 0.701 & 2,26 \\
\hline for fashion & 0.923 & 2,74 \\
\hline prestige & 1.027 & 3,08 \\
\hline to make friends & 1.098 & 3,25 \\
\hline ease to obtain & 1.050 & 3,33 \\
\hline risk of gold & 0.907 & 3,49 \\
\hline & & \\
\hline
\end{tabular}

The indicator of information from family is excluded because of the factor loadings less than 0.6. The fourth factor consists three indicators with the eigen value of 2,353. There are several variables support this factor, for example, variation in colors (X6), variation in feature (X7), variation in shapes (X8). Furthermore, the fifth factor includes only one factor with the eigen value of 0.732 . The indicator include in this factor is trend (X5). Lastly, the six factor consists of an indicator with the eigen value of 0.765 . As [37] used factor loading no less than 0.6 in his study to choose the final dimensions. The following table 4 presents the group variables in the factor and theirs factor loading.

TABLE IV. SUMMARY OF VARIABLES

\begin{tabular}{|c|l|c|}
\hline Factor & \multicolumn{1}{|c|}{ Indicators } & $\begin{array}{c}\text { Factor } \\
\text { Loadings }\end{array}$ \\
\hline 1. & benefit (X3) & 0,912 \\
& for treatment (X9) & 0,898 \\
& the history of gemstones (X11) & 0,781 \\
& public figure (X12) & 0,771 \\
\hline 2. & information from friends(X16) & 0,783 \\
& sales location(X18) & 0,761 \\
& prestige (X24) & 0,709 \\
& to make friend(X25) & 0,695 \\
& easy to obtain(X26) & 0,671 \\
& risk of gold (X27) & 0,806 \\
\hline 3. & modification of shell (X2) & 0,677 \\
& to support performance (X10) & 0,648 \\
& self confidence(X20) & 0,787 \\
& as a gift (X21) & 0,850 \\
\hline 4. & Variation in colors(X6) & 0,805 \\
& Variation in feature (X7) & 0,714 \\
& Variation in shapes(X8) & 0,834 \\
\hline 5. & trend (X5) & 0,732 \\
\hline 6. & family demand (X22) & 0,765 \\
\hline
\end{tabular}

\section{CONCLUSION}

This paper has emprically tested indicators that have underlying each factor in study within 162 respondents in the city of Palu in Indonesia. Exploratory factor analysis (EFA) was chosen to analyse data in this study. The results of this study shows that there are six factors which underlying consumers behavior to purchase gemstones in Indonesia. The total indicators in the factors is 19 and most of indicators are included in the factor 1, 2, and 3. Indicator (X3) has the most significant factor loadings and the supporting performance (X10) has low factor loadings. These findings tend to contribute to enrich the study of consumer behavior in luxury products. The future research may include the factors in this paper for further analysis with other variables in more large respodents and different data analysis.

\section{REFERENCES}

[1] Bourne, Francis S. 1957. -Group influence in marketing and public relations. In Some Applications of Behavioral Research. Eds. Renis Likert and Samuel P. Hayes. Basil, Switzerland: UNESCO.

[2] Mason, R.S.“Conspicuous consumption: A study of exceptional consumer behaviour”. Gower Publishing Company: Farnborough, UK. 1981.

[3] Bearden, W.O. and Michael J. E. "Reference group influence on product and brand purchase decisions", Journal of Consumer Research 9 (2): 183-194., 1982. 
[4] Horiuchi, Y. "A systems anomaly: Consumer decision-making process for luxury goods". Dissertation. University of Pennsylvania, Philadelphia, PA. 1984.

[5] Bushman, B.J.,"What is in a name?The moderating role of public selfconsciousness on the relation between brand label and brand preference", Journal of Applied Psychology 78 (5): 857-861., 1993.

[6] Pantzalis, I. "Exclusivity strategies in pricing and brand extension", unpublished doctoral dissertation. University of Arizona: Tucson, AZ, 1995.

[7] Eagly, A.H. and Shelly C. "The Psychology of Attitudes". New York: Harcourt Brace Jovanovich, 1993.

[8] Mandrik, C.A., "Consumer heuristics: the tradeoff between processing effort and brand value choice" Advances in Consumer Research 23: 301-307, 1996.

[9] Sallot, L. M.,"What the public thinks about public relations: an impression management experiment" Journalism and Mass Communication Quarterly 79 (1): 150-172, 2002.

[10] Hansen, F."From Life Style to Value Systems to Simplicity" In Advances in Consumer Research 25: 181-195. Eds. Joseph. W. Alba and J. Wesley Hutchinson., Provo, UT: Association for Consumer Research, 1998.

[11] Wong, N. Y. and Aaron C. A. 1998. "Personal taste and family face: luxury consumption in Confucian and Western societies" Psychology and Marketing 15 (5): 423-432. 1998.

[12] Vigneron, F. and Johnson., L.W. "A review and a conceptual framework of prestige-seeking consumer behavior", Academy of Marketing Science Review 1999 (1): 1-15. 1999.

[13] Vigneron, F. and Johnson., L.W. "Measuring perceptions of brand luxury", Journal of Brand Management 11 (6): 484-506.2004.

[14] Wong, A. and Judith L. Z.,"Understanding luxury brands in Hong Kong. European Advances in Consumer Research 4:310-316, 1999.

[15] Gentry, J.W., Sanjay P., Clifford S., and Commuri, S. "How now Ralph Lauren? The separation of brand and product in a counterfeit culture." Advances in Consumer Research 28: 258-265. 2001.

[16] Puntoni, S. "Self-identity and purchase intention: an extension of the theory of planned behavior" European Advances in Consumer Research 5: 130-134., 2001.

[17] Roth, W. E. "Consuming to achieve affective goals: a framework for analysis with application. Advances in Consumer Research 28: 217226, 2001.

[18] Miquel, S., Eva M. C., and Aldas-Manzano, J. "The effect of personal involvement to buy store brands" Journal of Product and Brand Management 11 (1): 6-18.2002.

[19] Coulter, R. A., Linda L. P., and Feick, L. "Rethinking the origins of involvement and brand commitment" Journal of Consumer Research 30 (2): 151-182. 2003.

[20] Eastman, J., Bill, F., David C., and S. Calvert. "The relationship between status consumption and materialism: cross-cultural comparison of
Chinese, Mexican, and American students." Journalof Marketing Theory and Practice 5 (1): 52-65. 1997.

[21] Leibenstein, H."Bandwagon, Snob, and Veblen Effects in the Theory of Consumers' Demand."Quarterly Journal of Economics 64 (May): 183207. 1950.

[22] Dubois, B. and Gilles, L. "Attitudes toward the concept of luxury: An exploratory analysis" inAsia-Pacific Advances in Consumer Research. Eds. Siew Meng Leong and Joseph A. Cote, 1, 2, 273-278. 1994.

[23] McKinsey. "The Luxury Industry: An Asset for France". Paris: McKinsey.1990

[24] Arghavan, $\mathrm{N}$ and Zaichkowsky,J.L. "Do counterfeits devalue the ownership of luxury brands?"Journal of Product and Brand Management 9 (7): 485-497, 2000.

[25] Schultz, P. W. and Lynnette C. Z. 1999. "Values As Predictors of Environmental Attitudes: EvidenceFor Consistency Across 14 Countries", Journal of Environmenta Psychology 19 (3): 255-265.,1999.

[26] Sheth, J.N., Bruce I. N., and Gross., B.I . "Why we buy what we buy: A theory of consumptionvalues. Journal of Business Research 22 (1): 159-170., 1991.

[27] Mazumdar, T."Experimental Investigation of the Psychological Determinants of Buyers' PriceAwareness and a Comparative Assessment of Methodologies for Retrieving Price Information from Memory" Working paper. Virginia Polytechnic Institute and State niversity.1986.

[28] Richins, M. and Scott D. 1992. "A consumer values orientation for materialism and its measurement:Scale development and validation" Journal of Consumer Research 19 (2): 303-316., 1992.

[29] Hirschman, E. C. and Morris B. H.. "Hedonic Consumption: Emerging Concepts, Methodsand Propositions". Journal of Marketing 46 (3): 92101. 1982.

[30] Brinberg, D. and Linda P."Self-Monitoring and Product Conspicuousness on Reference GroupInfluence", In Advances in Consumer Research 13. Eds. R. J. Lutz. Provo, UT.: Association for Consumer Research, 1986.

[31] Kim, J. S. "Assessing the causal relationships among materialism, reference group, and conspicuousconsumption of Korean adolescents". Consumer Interests Annual 44: 155. 1998.

[32] Nunnally, J., "Psychometric Theory", McGraw-Hill, New york, 1978.

[33] Hair, J., Anderson, R., Tatham, R. and Black, W. "Multivariate Data Analysis, 4th ed.,Prentice Hall, Englewood Cliffs, NJ. 1995.

[34] Bagozzi, R.P., Yi, Y. (1998). On the evaluation of structure equation models, Academy of Marketing Science, Vol. 16 No. 1, pp. 76-94.

[35] Hair, J., Anderson, R., Tatham, R. and Black, W. "Multivariate Data Analysis, 4th ed.,Prentice Hall, Englewood Cliffs, NJ. 1995.

[36] Tabachnick, B.G. and Fidell, L.S. (1989), Using Multivariate Statistic, HarperCollins, London.

[37] Brotherton, B.,"Critical success factors in UK budget hotel operations", International Journal of Operations \& Production Management, Vol. 24 Iss: 9 pp. $944-969,2004$. 